\title{
Flat epithelial atypia in directional vacuum-assisted biopsy of breast microcalcifications: surgical excision may not be necessary
}

\author{
Zulfia McCroskey $^{1} \cdot$ Nour Sneige $^{1} \cdot$ Carolyn R Herman $^{2} \cdot$ Ross A Miller $^{1} \cdot$ Luz A Venta $^{2} \cdot$ Jae Y Ro $^{1} \cdot$ Mary R Schwartz $^{1}$. \\ Alberto G Ayala ${ }^{1}$
}

Received: 15 October 2017 / Revised: 5 January 2018 / Accepted: 7 January 2018 / Published online: 21 February 2018

(c) United States \& Canadian Academy of Pathology 2018

\begin{abstract}
The aim of this study was to analyze the clinicopathological features of patients with flat epithelial atypia, diagnosed in directional vacuum-assisted biopsy targeting microcalcifications, to identify upgrade rate to in situ ductal or invasive breast carcinoma, and determine factors predicting carcinoma in the subsequent excision. We retrospectively evaluated the histological, clinical, and mammographic features of 69 cases from 65 women, with directional vacuum-assisted biopsydiagnosed flat epithelial atypia with or without atypical ductal hyperplasia or atypical lobular hyperplasia, which underwent subsequent surgical excision. The extent and percentage of microcalcifications sampled by directional vacuumassisted biopsy were evaluated by mammography. All biopsy and surgical excision slides were reviewed. The age of the women ranged from 40 to 85 years (mean 57 years). All patients presented with mammographically detected microcalcifications only, except in one case that had associated architectural distortion. Extent of calcifications ranged from $<1 \mathrm{~cm}(n=47), 1-3 \mathrm{~cm}(n=15)$ to $>3 \mathrm{~cm}(n=6)$, and no measurement $(n=1)$. A mean of 11 cores (range 6-25) was obtained from each lesion. Post-biopsy mammogram revealed $>90 \%$ removal of calcifications in $81 \%$ of cases. Pure flat epithelial atypia represented nearly two-thirds of directional vacuum-assisted biopsy specimens $(n=43,62 \%)$, while flat epithelial atypia coexisted with atypical ductal hyperplasia (18 cases, 26\%), or atypical lobular hyperplasia (8 cases, $12 \%)$. Upon excision, none of the cases were upgraded to in situ ductal or invasive breast cancer. In one case, however, an incidental, tubular carcinoma $(4 \mathrm{~mm})$ was found away from biopsy site. Excluding this case, the upgrade rate was $0 \%$. Our study adds to the growing evidence that diagnosis of flat epithelial atypia on directional vacuum-assisted biopsy for microcalcifications as the only imaging finding is not associated with a significant upgrade to carcinoma on excision, and therefore, excision may not be necessary. Additionally, excision may not be necessary for flat epithelial atypia with atypical ductal hyperplasia limited to $\leq 2$ terminal duct-lobular units, if at least $90 \%$ of calcifications have been removed on biopsy.
\end{abstract}

\section{Introduction}

With the widespread use of screening mammography, columnar cell lesions, which often calcify, are recognized with increasing frequency on core needle biopsy. They have

Nour Sneige

NSneige@ houstonmethodist.org

1 Department of Pathology and Genomic Medicine, Houston Methodist Hospital, Houston, TX 77098, USA

2 The Methodist Breast Center Imaging, Houston Methodist Hospital, Houston, TX 77098, USA been divided into columnar cell change and columnar cell hyperplasia with or without atypia [1]. To standardize the terminology, the World Health Organization (WHO) Working Group on the Pathology and Genetics of Tumors of the Breast designated columnar cell lesions with atypia as flat epithelial atypia [2].

While the histologic hallmark of columnar cell lesions is the presence of variably dilated acini lined by one to two layers of columnar epithelial cells with apical snouts, in flat epithelial atypia, the lining epithelium is composed of one to several layers of cuboidal to columnar epithelial cells having cytological atypia of low-grade or monomorphic type [2]. It must be noted that lesions of this type have been named by Azzopardi as "clinging carcinoma, monomorphic 
type". However, in current practice, only lesions with high-grade nuclei are regarded as clinging ductal carcinoma in situ [2-4].

Several studies have demonstrated that columnar cell lesions and flat epithelial atypia share similar molecular alterations with atypical hyperplasia and low-grade carcinoma in the same tissue section [5-11]. Although the natural history of flat epithelial atypia is less well understood than that of atypical ductal hyperplasia or atypical lobular hyperplasia, the available data suggest that the risk of breast cancer development is lower than in the other types of atypia [4, 12-16]. For example, in the study by Boulos et al. [15], the authors observed a positive association between columnar cell lesions (including columnar cell hyperplasia and flat epithelial atypia) and atypical hyperplasia, however, the presence of columnar cell lesions alone was associated with only mild increase in the overall cancer risk (relative risk $=1.47 ; p=0.05$ ), with no significant risk difference observed among the three categories of columnar cell lesions. Additionally, the relative risk of invasive breast cancer for women with both atypical ductal hyperplasia and columnar cell lesions compared to those with atypical ductal hyperplasia alone did not differ significantly (relative risk $=1.55, p=0.29$ ). Said et al. [16] demonstrated that flat epithelial atypia did not increase the risk of breast cancer in women with atypical ductal hyperplasia and that the risk associated with flat epithelial atypia is comparable to that of patients with proliferative lesions without atypia.

The clinical significance and management of flat epithelial atypia diagnosed on core needle biopsies is still a subject of debate [17-41]. Flat epithelial atypia is frequently associated with lesions of higher concern, including ductal carcinoma in situ, and lobular neoplasia, as well as invasive tubular and lobular carcinomas [42]. Therefore, there is concern that a cancerous lesion may be missed when flat epithelial atypia alone is encountered in core needle biopsy samples. Published studies have reported an upgrade rate to in situ or invasive carcinoma in the follow-up excision after a diagnosis of flat epithelial atypia on core needle biopsy in up to $20 \%$ of cases [36-41, 43]. Although several authors have advocated for clinical follow-up, if flat epithelial atypia is the worst pathologic finding in the core needle biopsy and all the calcifications are removed by core biopsy [1729], others recommend follow-up excision to rule out a higher risk lesion [30-41, 43].

The aim of this study was to analyze the clinicopathological features of patients with flat epithelial atypia, diagnosed on directional vacuum-assisted biopsy targeting microcalcifications, to identify the upgrade rate to ductal carcinoma in situ or invasive breast carcinoma, and to determine factors predicting the presence of carcinoma in the subsequent excision.

\section{Materials and methods}

After obtaining institutional review board approval, the Houston Methodist Hospital pathology database was searched, between January 2006 and December 2016, for stereotactic-guided core needle biopsy specimens, procured for assessment of microcalcifications as the only mammographic abnormality. The specimens were interpreted as flat epithelial atypia, with or without atypical ductal hyperplasia and or atypical lobular hyperplasia or lobular carcinoma in situ. Exclusion criteria were the presence of ipsilateral breast cancer (either ductal carcinoma in situ or invasive breast cancer), absence of follow-up surgical excision, and Breast Imaging Reporting and Data System (BI-RADS) score 5 (which require excision).

All core needle biopsies were performed using the directional vacuum-assisted biopsy procedure with 11-g or 9-g needles. Mammographic characteristics of the microcalcifications were retrospectively evaluated by a breast imaging specialist using the American College of Radiology BI-RADS guidelines. The core needle biopsy specimens were radiographed to confirm the presence of calcifications. Post-biopsy radiographs were reviewed to evaluate for residual calcifications after the directional vacuum-assisted biopsy procedure. Clinical data and mammographic features, such as extent of microcalcifications categorized as $<1 \mathrm{~cm}, 1-3 \mathrm{~cm}$, and $>3 \mathrm{~cm}$, and the percentage of microcalcifications removed by directional vacuum-assisted biopsy as $<50,50-90$, and $>90 \%$ were recorded. After confirming the presence of microcalcifications, tissue cores were placed in $10 \%$ buffered formalin and processed for histologic evaluation.

All directional vacuum-assisted biopsy slides were retrieved and retrospectively reviewed by a dedicated breast pathologist (NS) to confirm the diagnosis of flat epithelial atypia as the dominant lesion. In each case, five-level cuts, at 50 micron intervals, were routinely obtained and stained with hematoxylin and eosin for histologic evaluation. Flat epithelial atypia was identified on the basis of the WHO criteria [2]. These criteria include enlarged, variably dilated acini lined by one to several layers of a single epithelial cell type that lack polarity. The nuclei are usually round to oval and uniform, and have inconspicuous nucleoli, similar in appearance to the nuclei characterizing low-grade ductal carcinoma in situ. The cells may be cuboidal to columnar, often with apical cytoplasmic snouts. In some cases, the nuclei may retain a more oval shape and an orientation perpendicular to the basement membrane, resembling the pattern observed in colonic tubular adenoma. However, in contrast to the slender bland nuclei of columnar cell lesion with hyperplasia, chromatin may show clumping and margination with an increased nuclear to cytoplasmic ratio [1]. The number of terminal duct-lobular units, involved by flat 
epithelial atypia, were recorded. Their cell features, whether oval round or tall columnar, were noted. In cases with associated atypical ductal hyperplasia, atypical ductal hyperplasia was further quantified as $\leq 2$ terminal ductlobular units or $>2$ terminal duct-lobular units involvement based on previously published criteria [44-46].

One case retrospectively interpreted as showing a microscopic focus of tubular carcinoma, was considered a false negative. The diagnosis in this case was confirmed by the absence of myoepithelial cells utilizing an antibody for smooth muscle myosin heavy chain (prediluted clone SMMH-1, Agilent, Santa Clara, CA, USA), on a destained slide from one of the original directional vacuum-assisted biopsy H\&E slides.

All slides of the surgical excision specimens were also reviewed, and the findings were recorded and compared to those of the directional vacuum-assisted biopsy specimens. The presence of ductal carcinoma in situ or invasive breast cancer in the surgical excision specimen was regarded as an upgrade.

\section{Results}

There were a total of 97 directional vacuum-assisted biopsy specimens from 92 women with a diagnosis of flat epithelial atypia, with or without atypical ductal hyperplasia or atypical lobular hyperplasia. Of these, 28 cases were excluded from the study either due to lack of follow-up surgical excision (eight cases), presence of atypical ductal hyperplasia as the predominant component (13 cases) with flat epithelial atypia constituting only a minor to a negligible component of the lesion, or disagreement with original diagnoses ( 7 cases, detailed below). The final study group included 69 directional vacuum-assisted biopsies from 65 women, constituting the subject of this study.

\section{Clinical and mammographic findings}

The clinical and mammographic findings are presented in Table 1 . The age of the women ranged from 40 to 85 years, with a mean age of 57 years. All patients presented with mammographically detected microcalcifications only, except in one case that had associated architectural distortion. Mammographically, all cases were classified as BIRADS 4. The extent of microcalcifications detected on mammography ranged from less than $1 \mathrm{~cm}$ to over $3 \mathrm{~cm}$. In one case, no pre-stereotactic image was available for measurement of calcifications. In 56/69 (81\%) cases, directional vacuum-assisted biopsy was performed with a 9-g needle, whereas in the rest of the cases, an 11-g needle was used. A mean of 11 cores (range, 6-25) was obtained from each lesion. Post-biopsy mammograms revealed that more than
Table 1 Clinicopathologic characteristics of cases included in the study $($ total $=69)$

\begin{tabular}{|c|c|c|c|}
\hline & $\begin{array}{l}\text { Pure flat } \\
\text { epithelial } \\
\text { atypia }\end{array}$ & $\begin{array}{l}\text { Flat epithelial } \\
\text { atypia }+ \\
\text { atypical ductal } \\
\text { hyperplasia }\end{array}$ & $\begin{array}{l}\text { Flat epithelial } \\
\text { atypia }+ \\
\text { atypical } \\
\text { lobular } \\
\text { hyperplasia }\end{array}$ \\
\hline No. of biopsies & $43(62 \%)$ & $18(26 \%)$ & $8(12 \%)$ \\
\hline Age, mean (range) & $59.5(40-82)$ & $57(43-85)$ & $59(43-71)$ \\
\hline \multicolumn{4}{|c|}{ Mammographic indication for biopsy } \\
\hline Microcalcifications & $43(62 \%)$ & $17(25 \%)$ & $8(12 \%)$ \\
\hline \begin{tabular}{l}
\multicolumn{1}{c}{ Architectural } \\
distortion associated \\
with calcifications
\end{tabular} & 0 & $1(1 \%)$ & 0 \\
\hline \multicolumn{4}{|l|}{ Size of calcifications } \\
\hline$<1 \mathrm{~cm}$ & $33(48 \%)$ & $10(15 \%)$ & $4(6 \%)$ \\
\hline $1-3 \mathrm{~cm}$ & $6(9 \%)$ & $5(7 \%)$ & $4(6 \%)$ \\
\hline$>3 \mathrm{~cm}$ & $4(5 \%)$ & $2(3 \%)$ & 0 \\
\hline $\begin{array}{l}\text { No prior image for } \\
\text { accurate measurement }\end{array}$ & 0 & $1(1 \%)$ & 0 \\
\hline \multicolumn{4}{|l|}{ Needle gauge } \\
\hline $9 \mathrm{~g}$ & $33(48 \%)$ & $15(22 \%)$ & $8(12 \%)$ \\
\hline $11 \mathrm{~g}$ & $10(14 \%)$ & $3(4 \%)$ & 0 \\
\hline $\begin{array}{l}\text { Number of cores, } \\
\text { mean (range) }\end{array}$ & $12(8-16)$ & $12(7-25)$ & 12 \\
\hline \multicolumn{4}{|c|}{ Percent of calcifications removed } \\
\hline$<50 \%$ & 0 & $1(1 \%)$ & 0 \\
\hline $50-90 \%$ & $6(8 \%)$ & $4(6 \%)$ & $2(3 \%)$ \\
\hline$>90 \%$ & $37(54 \%)$ & $13(19 \%)$ & $6(9 \%)$ \\
\hline \multicolumn{4}{|l|}{ Breast density } \\
\hline $\begin{array}{l}\text { Almost entirely } \\
\text { fatty }\end{array}$ & $3(4 \%)$ & 0 & 0 \\
\hline Scattered & $3(4 \%)$ & $5(7 \%)$ & 0 \\
\hline $\begin{array}{l}\text { Heterogeneous or } \\
\text { extremely dense }\end{array}$ & $37(54 \%)$ & $13(19 \%)$ & $8(12 \%)$ \\
\hline BI-RADS score & 4 & 4 & 4 \\
\hline
\end{tabular}

$90 \%$ of calcifications had been removed in 56 of 69 cases $(81 \%)$.

\section{Histologic findings of directional vacuum-assisted biopsy specimens}

The majority of flat epithelial atypia cases (32 cases, 46.4\%) exhibited mixed oval round and tall columnar cell features; 28 cases $(40.5 \%)$ were of the oval round cell type and 9 cases $(13 \%)$ were of the tall cell variant (Fig. 1). In most cases $(71 \%)$, flat epithelial atypia involved $>2$ terminal duct-lobular units. Forty-three $(62 \%)$ cases were pure flat epithelial atypia, and the remaining $26(38 \%)$ cases were flat epithelial atypia coexisting with atypical ductal hyperplasia (18 cases, 26\%) (Fig. 1e, f), or atypical lobular hyperplasia 
Fig. 1 Examples of flat epithelial atypia demonstrating round to oval (a, b H\&E stain, x125) and tall columnar cell features $(\mathbf{c}, \mathbf{d}$ same cases as shown in $\mathbf{a}$ and $\mathbf{b}$, respectively, $\mathrm{H} \& \mathrm{E}$ stain, $\times 250$ ). There is a loss of cell polarity with slight nuclear hyperchromasia. Another example of flat epithelial atypia, with pure tall columnar cells $(\mathbf{e}, \mathbf{f})$. One of the ducts displays a cribriform arrangement representing focal atypical ductal hyperplasia (e). Incipient cartwheels are also noted (f). (e, f H\&E stain $\times 250$ )
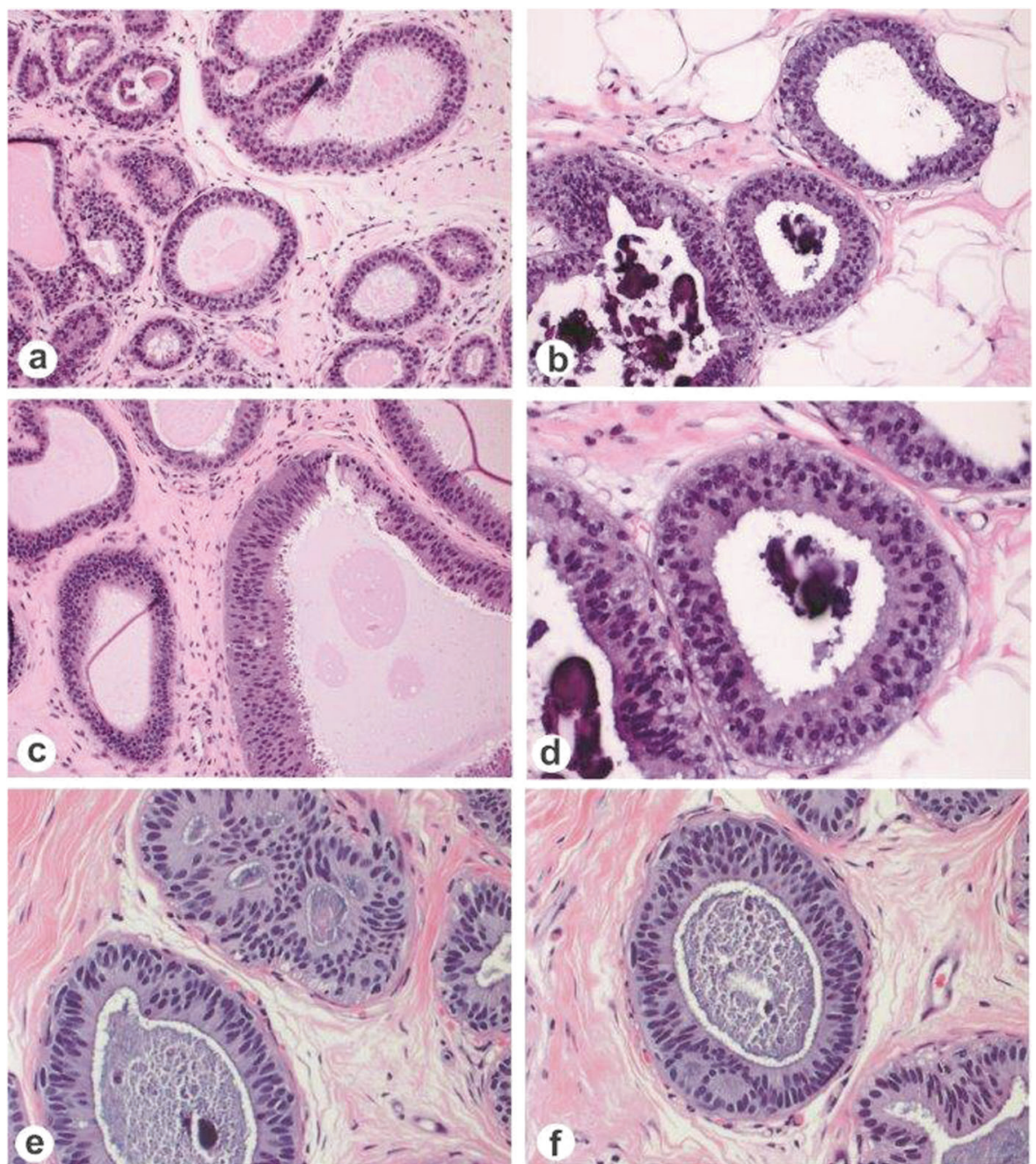

(8 cases, 12\%). Atypical ductal hyperplasia constituted less than 2 terminal duct-lobular units in 10 cases (56\%).

\section{Histologic findings of subsequent excisional specimens}

All subsequent surgical excisions were performed within few months (mean 2 months, range 25 days -7 months) after initial directional vacuum-assisted biopsy. None of the cases were upgraded to ductal carcinoma in situ or invasive breast cancer upon excision. In one case, however, an incidental $4 \mathrm{~mm}$ nodule of tubular carcinoma was found in the surgical excision specimen at several centimeters away from the biopsy site. In this case, calcifications ranged from 1 to $3 \mathrm{~cm}$, with 50 to $90 \%$ of them being removed by directional vacuum-assisted biopsy. The corresponding directional vacuum-assisted biopsy specimens contained only flat epithelial atypia with microcalcifications. The remaining 68 surgical excision specimens showed no residual epithelial atypia in 31 cases $(45 \%)$, residual focal pure flat epithelial atypia in 15 cases $(23 \%)$, residual flat epithelial atypia coexisting with atypical ductal hyperplasia, or atypical ductal hyperplasia and atypical lobular hyperplasia in 12 cases (17.4\%). In 10 other cases, residual atypical lobular hyperplasia, atypical ductal hyperplasia, or atypical ductal hyperplasia and atypical lobular hyperplasia with no accompanied flat epithelial atypia were present in 8 $(11.6 \%)$, and one each (1.4\%), respectively.

The upgrade rate of flat epithelial atypia in this study is $1.4 \%$ if the case of incidental tubular carcinoma is included. Excluding this case of incidental finding (away from the biopsy site), the upgrade rate of flat epithelial atypia is $0 \%$.

\section{Histologic findings of the directional vacuum- assisted biopsy specimens with disagreement in diagnosis}

Seven cases were considered to be in disagreement with the original biopsy diagnosis of flat epithelial atypia. These were a tubular carcinoma in association with flat epithelial atypia and atypical ductal hyperplasia that was missed on the initial directional vacuum-assisted biopsy specimen (one 
Fig. 2 Examples of directional vacuum-assisted biopsy cases with disagreement in diagnosis (upgraded or downgraded from flat epithelial atypia): Small round acinar structures $(<1 \mathrm{~mm}$ area) of tubular carcinoma that was missed in the core needle biopsy specimen (a). Absence of myoepithelial cells confirmed by negative staining for smooth muscle myosin heavy chain (b). Flat epithelial atypia with microcalcifications in the same biopsy site (a, c H\&E stain, $\times 250$; b immunohistochemical stain $\times 250$ ) (see text for further details). An example of a case that was downgraded from flat epithelial atypia characterized by dilated acini with luminal secretion, lined by one to multiple cell layers with cell features characteristic of usual duct hyperplasia rather than flat epithelial atypia (d, e H\&E stain, $\times 125$ and $\times 250$, respectively)
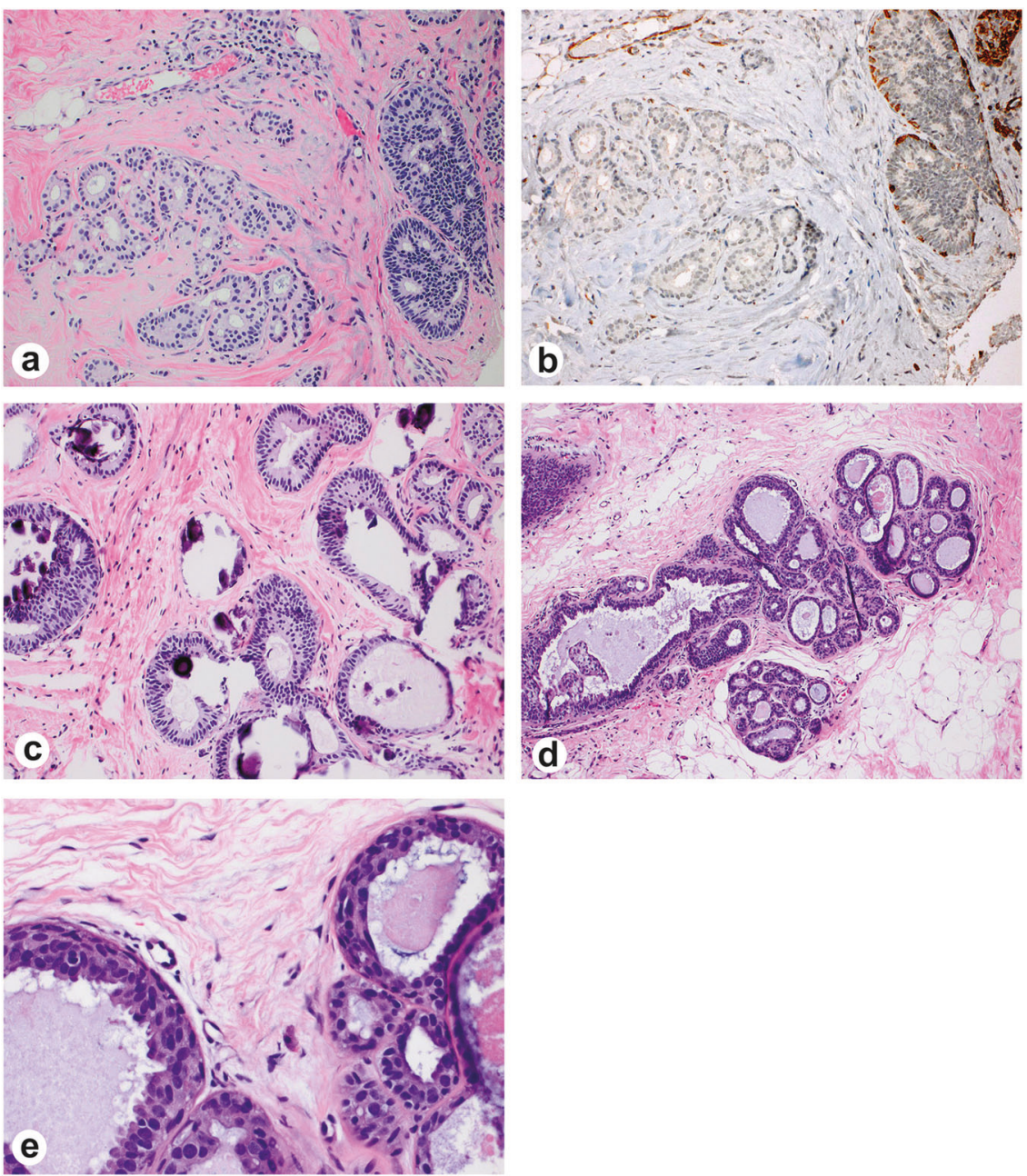

case) (Fig. 2a-c), blunt duct adenosis (2 cases), columnar cell change with associated usual duct hyperplasia (three cases) (Fig. 2d, e), and high-grade atypia bordering on highgrade ductal carcinoma in situ (one case). In the case of tubular carcinoma, an immunohistochemical stain for myoepithelial cells, using an antibody for SMMH-1, was performed on the destained slide from one of the original needle biopsy H\&E slides, which demonstrated a complete loss of myoepithelial cells, confirming the diagnosis of tubular carcinoma.

\section{Discussion}

In our study, the upgrade rate of flat epithelial atypia in directional vacuum-assisted biopsy of breast microcalcifications to carcinoma on excision was $0 \%$ (excluding the case of incidental tubular carcinoma). Our findings add to the growing evidence that diagnosis of pure flat epithelial atypia on directional vacuum-assisted biopsy for microcalcifications as the only imaging finding is not associated with a significant upgrade to carcinoma on excision
[17-29]. Our study also showed that even when flat epithelial atypia is associated with atypical ductal hyperplasia limited to $<3$ terminal duct-lobular units, there is no significant upgrade to carcinoma. This finding is also in line with previous reports showing that limited atypical ductal hyperplasia diagnosed on directional vacuum-assisted biopsy is not significantly associated with a higher risk lesion provided that most of the calcifications have been removed on biopsy [44-46].

The upgrade rate for flat epithelial atypia in the literature varies from 0 to $20 \%$ for pure flat epithelial atypia [17-41,43]. As a result, there is no consensus about the management of these lesions when detected on core needle biopsies (Tables 2 and 3). Factors influencing diagnostic results may include: lesion characteristics (mass vs. calcifications only), accuracy in targeting the lesion, sampling techniques (vacuum vs. cutting needle), number of core biopsy samples and needle gauge, percentage of calcifications removed, degree of mammographic suspicion (BIRADS 4 vs. BI-RADS 5), as well as variable histologic interpretation. In a meta-analysis of 25 studies [43], the authors noted a trend toward a lower underestimation rate 


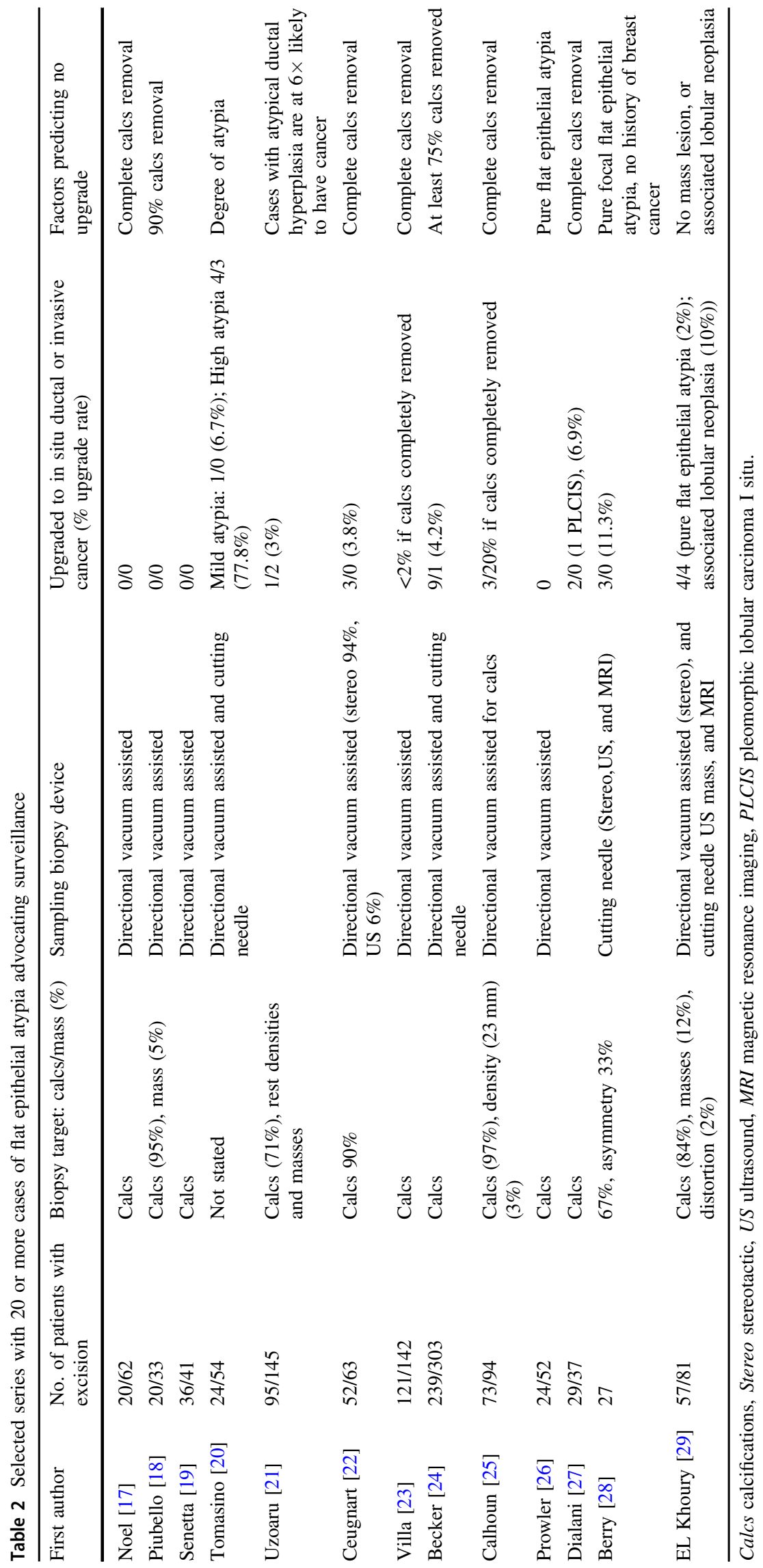




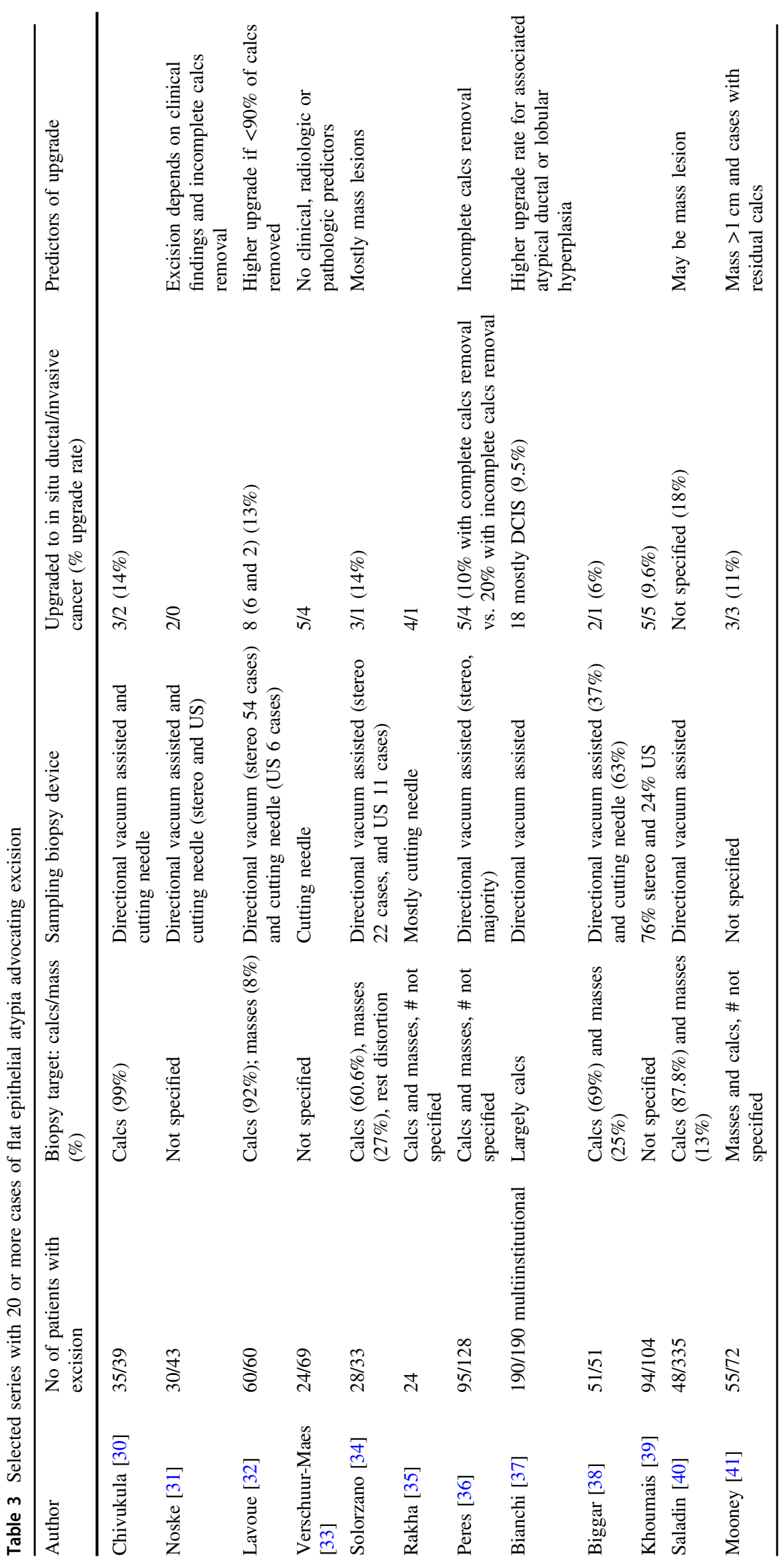


with use of directional vacuum-assisted biopsy vs. regular cutting needle biopsy, but these differences were not significant. However, the impact of other factors in these studies could not be determined due to their retrospective nature, and missing and heterogeneous data.

Review of published reports that included 20 or more cases of flat epithelial atypia with subsequent excision (totaling 734 cases among 12 reports) [30-41] showed that a higher upgrade rate is encountered among cases that included calcifications associated with masses or other mammographic abnormalities, biopsy samples procured by cutting needles, and limited sampling of calcifications. For example, in a large retrospective multiinstitutional study by Bianchi et al. [37], the authors noted a trend for higher upgrade rate in cases with incomplete removal of calcifications, associated mass or architectural distortion (9\% of cases), and lesions with BI-RADS 4 and 5 combined (23\% of cases). Similarly, in the series by Peres et al. [36], the upgrade rate was higher for cases with incomplete calcifications vs. those with removal of calcification (20\% vs. $10 \%$, respectively).

Conversely, in series advocating surveillance (totaling 986 cases among 15 studies including current study) [17-29], the authors found no or a low upgrade rate in cases where at least $75 \%$ of calcifications were removed. Of note, in 10 of the 15 series, calcifications accounted for targets of almost all cases with only a few series including masses or architectural distortion. The technique of directional vacuum-assisted biopsy was used for removal of more than $90 \%$ of calcifications.

At the histologic levels, although diagnostic criteria for flat epithelial atypia are clearly defined and followed, the diagnosis of flat epithelial atypia remains challenging. Blunt duct adenosis and lactational changes may be misinterpreted as flat epithelial atypia [47]. Our excluded samples, due to histologic disagreement (seven cases) with the original diagnosis of flat epithelial atypia, represent typical examples of such cases. Among these seven cases, five were downgraded from flat epithelial atypia to columnar cell change with usual ductal hyperplasia, or blunt duct adenosis, and two were upgraded, one to "bordering on DCIS", and the other to tubular carcinoma. In a study of 130 cases of flat epithelial atypia, Tomasino et al. [20] reclassified 16 as usual ductal hyperplasia and 60 as columnar cell hyperplasia. These authors also noted that the presence of atypia higher than mild cytological atypia was associated with higher upgrade rate. In their series, the UR was $6.7 \%$ for pure flat epithelial atypia with mild cytologic atypia vs. $77.8 \%$ for pure flat epithelial atypia with marked cytologic atypia. The inclusion of high-grade atypia in the flat epithelial atypia group raises a concern about the adherence to flat epithelial atypia diagnostic criteria and accuracy of flat epithelial atypia diagnosis, since by definition, flat epithelial atypia is a low-grade lesion. Lesions with high-grade atypia are best interpreted as bordering on ductal carcinoma in situ and require surgical excision. While the inclusion of flat epithelial atypia mimickers (i.e., blunt duct adenosis and associated usual ductal hyperplasia) may result in a lower upgrade rate, the inclusion of cases with moderate- to high-grade atypia may result in a higher upgrade rate, and hence recommendation for excision. Therefore, in some cases, familiarity with the diagnostic pitfalls and use of immunohistochemical stains (high molecular weight cytokeratin and estrogen receptor) facilitate correct diagnosis [47].

Several studies have compared the upgrade rate in flat epithelial atypia with or without associated atypical ductal hyperplasia, and found that in cases with associated atypical ductal hyperplasia, the upgrade rate is significantly higher than in cases with pure flat epithelial atypia $[18,21,26]$. However, no quantitation of the extent of atypical ductal hyperplasia was applied. In atypical ductal hyperplasia studies that evaluated the upgrade rate in relation to the extent of lesions [43-45], we and others have demonstrated that limited atypical ductal hyperplasia, sampled by directional vacuum-assisted biopsy and with no significant cytologic atypia, is associated with low upgrade rate, provided that $>90 \%$ of the calcifications were sampled. In this series, the presence of limited atypical ductal hyperplasia, either in association with flat epithelial atypia or as a separate focus, did not influence the upgrade rate. Additionally, the presence of associated atypical lobular hyperplasia did not influence the upgrade rate. This is in contrast to previous reports where associated lobular neoplasia resulted in upgrade in up to $10 \%$ of cases [29].

In conclusion, our study adds to the growing evidence that diagnosis of flat epithelial atypia on directional vacuum-assisted biopsy for microcalcifications as the only imaging finding is not associated with a significant upgrade to carcinoma on excision. This provides the clinician with the managment options of clinical and imaging follow-up, rather than provoking a reflex reaction to surgical excision to the diagnosis of flat epithelial atypia. Additionally, excision may not be necessary for flat epithelial atypia with atypical ductal hyperplasia limited to $\leq 2$ terminal ductlobular units, provided that at least $90 \%$ of the calcifications have been removed on directional vacuum-assisted biopsy. Overall, the optimal management of flat epithelial atypia diagnosed on directional vacuum-assisted biopsy depends on the ability to precisely recognize this entity and a multidisciplinary approach involving radiologists, pathologists, surgeons, and oncologists in the decisionmaking for management of such cases. It is important to note that our study included only BI-RADS 4 microcalcifications, which were not associated with masses or other palpable or mammographic findings 


\section{Compliance with ethical standards}

Conflict of interest The authors declare that they have no conflict of interest.

\section{References}

1. Schnitt SJ, Vincent-Salomon A. Columnar cell lesions of the breast. Adv Anat Pathol. 2003;10:113-24.

2. Schnitt SJ, Collins L, Lakhani SR. Flat epithelial atypia. In: Lakhani SR, Ellis IO, Schnitt SJ, Tan PH, van der Vijver MJ, editors. World health organization classification of tumours. 4th ed. Lyon, France: International Agency for Research on Cancer (IARC); 2012. p. 87.

3. Azzopardi JG, Ahmed A, Millis RR. Problems in breast pathology. Major Probl Pathol. 1979;11:i-xvi.

4. Eusebi V, Foschini MP, Cook MG, et al. Long-term follow-up of in situ carcinoma of the breast with special emphasis on clinging carcinoma. Semin Diagn Pathol. 1989;6:165-73.

5. Moinfar F, Man YG, Bratthauer GL, et al. Genetic abnormalities in mammary ductal intraepithelial neoplasia-flat type ("clinging ductal carcinoma in situ"): a simulator of normal mammary epithelium. Cancer. 2000;88:2072-81.

6. Dabbs DJ, Carter G, Fudge M, et al. Molecular alterations in columnar cell lesions of the breast. Mod Pathol. 2006;19:344-9.

7. Simpson PT, Gale T, Reis-Filho JS, et al. Columnar cell lesions of the breast: the missing link in breast cancer progression?: a morphological and molecular analysis. Am J Surg Pathol. 2005;29:734-46.

8. Abdel-Fatah TM, Powe DG, Hodi Z, et al. Morphologic and molecular evolutionary pathways of low nuclear grade invasive breast cancers and their putative precursor lesions: further evidence to support the concept of low nuclear grade breast neoplasia family. Am J Surgl Pathol. 2008;32:513-23.

9. Verschuur-Maes AH, Moelans C, de Bruin P, et al. Analysis of gene copy number alterations by multiplex ligation-dependent probe amplification in columnar cell lesions of the breast. Cell Oncol. 2014;37:147-54.

10. Aulmann S, Elsawaf Z, Penzel R, et al. Invasive tubular carcinoma of the breast frequently is clonaly related to flat epithelial atypia and low-grade ductal carcinoma in situ. Am J Surg Pathol. 2009;33:1646-53.

11. Schnitt SJ. Clinging carcinoma: an American perspective. Semin Diagn Pathol. 2010;27:31-36.

12. Bijker N, Peterse JL, Duchateau L, et al. Risk factors for recurrence and metastasis after breast-conserving therapy for ductal carcinoma-in-situ: analysis of European Organization for Research and Treatment of Cancer Trial 10853. J Clin Oncol. 2001;19:2263-71.

13. Martel M, Barron-Rodriguez P, Tolgay Ocal I, et al. Flat DIN 1 (flat epithelial atypia) on core needle biopsy: 63 cases identified retrospectively among 1,751 core biopsies performed over an 8year period (1992-1999). Virchows Arch. 2007;451:883-91.

14. de Mascarel I, MacGrogan G, Mathoulin-Pélissier S, et al. Epithelial atypia in biopsies performed for microcalcifications. practical considerations about 2,833 serially sectioned surgical biopsies with a long follow-up. Virchows Arch. 2007;451:1-10.

15. Boulos FI, Dupont WD, Simpson JF, et al. Histologic associations and long-term cancer risk in columnar cell lesions of the breast: a retrospective cohort and a nested case-control study. Cancer. 2008;113:2415-21.

16. Said SM, Visscher DW, Nassar A, et al. Flat epithelial atypia and risk of breast cancer: a Mayo cohort study. Cancer. 2015;121: $1548-55$.
17. Noël JC, Buxant F, Engohan-Aloghe C. Immediate surgical resection of residual microcalcifications after a diagnosis of pure flat epithelial atypia on core biopsy: a word of caution. Surg Oncol. 2010;19:243-6.

18. Piubello Q, Parisi A, Eccher A, et al. Flat epithelial atypia on core needle biopsy: which is the right management? Am J Surg Pathol. 2009;33:1078-84.

19. Senetta R, Campanino PP, Mariscotti G, et al. Columnar cell lesions associated with breast calcifications on vacuum-assisted core biopsies: clinical, radiographic, and histological correlations. Mod Pathol. 2009;22:762-9.

20. Tomasino RM, Morello V, Gullo A, et al. Assessment of "grading" with Ki-67 and c-kit immunohistochemical expressions may be a helpful tool in management of patients with flat epithelial atypia (FEA) and columnar cell lesions (CCLs) on core breast biopsy. J Cell Physiol. 2009;221:343-9.

21. Uzoaru I, Morgan BR, Liu ZG, et al. Flat epithelial atypia with and without atypical ductal hyperplasia: to re-excise or not. Results of a 5-year prospective study. Virchows Arch. 2012;461:419-23.

22. Ceugnart L, Doualliez V, Chauvet MP, et al. Pure flat epithelial atypia: is there a place for routine surgery? Diagn Interv Imaging. 2013;94:861-9.

23. Villa A, Chiesa F, Massa T, et al. Flat epithelial atypia: comparison between 9-gauge and 11-gauge devices. Clin Breast Cancer. 2013;13:450-4.

24. Becker AK, Gordon PB, Harrison DA, et al. Flat ductal intraepithelial neoplasia $1 \mathrm{~A}$ diagnosed at stereotactic core needle biopsy: is excisional biopsy indicated? AJR Am J Roentgenol. 2013;200:682-8.

25. Calhoun BC, Sobel A, White RL, et al. Management of flat epithelial atypia on breast core biopsy may be individualized based on correlation with imaging studies. Mod Pathol. 2015;28:670-6.

26. Prowler VL, Joh JE, Acs G, et al. Surgical excision of pure flat epithelial atypia identified on core needle breast biopsy. Breast. 2014;23:352-6.

27. Dialani V, Venkataraman S, Frieling G, et al. Does isolated flat epithelial atypia on vacuum-assisted breast core biopsy require surgical excision? Breast J. 2014;20:606-14.

28. Berry JS, Trappey AF, Vreeland TJ, et al. Analysis of clinical and pathologic factors of pure, flat epithelial atypia on core needle biopsy to aid in the decision of excision or observation. J Cancer. 2016;7:1-6.

29. El Khoury M, Sanchez LM, Lalonde L, et al. Is the outcome at surgery different when flat epithelial atypia and lobular neoplasia are found in association at biopsy? $\mathrm{Br} \mathrm{J}$ Radiol. 2017;90: 20160750.

30. Chivukula M, Bhargava R, Tseng G, et al. Clinicopathologic implications of "flat epithelial atypia" in core needle biopsy specimens of the breast. Am J Clin Pathol. 2009;131:802-8.

31. Noske A, Pahl S, Fallenberg E, et al. Flat epithelial atypia is a common subtype of B3 breast lesions and is associated with noninvasive cancer but not with invasive cancer in final excision histology. Hum Pathol. 2010;41:522-7.

32. Lavoué V, Roger CM, Poilblanc M, et al. Pure flat epithelial atypia (DIN 1a) on core needle biopsy: study of 60 biopsies with follow-up surgical excision. Breast Cancer Res Treat. 2011;125:121-6.

33. Verschuur-Maes AH, Witkamp AJ, de Bruin PC, et al. Progression risk of columnar cell lesions of the breast diagnosed in core needle biopsies. Int J Cancer. 2011;129:2674-80.

34. Solorzano S, Mesurolle B, Omeroglu A, et al. Flat epithelial atypia of the breast: pathological-radiological correlation. AJR Am J Roentgenol. 2011;197:740-6.

35. Rakha EA, Lee AH, Jenkins JA, et al. Characterization and outcome of breast needle core biopsy diagnoses of lesions of 
uncertain malignant potential (B3) in abnormalities detected by mammographic screening. Int J Cancer. 2011;129:1417-24.

36. Peres A, Barranger E, Becette V, et al. Rates of upgrade to malignancy for 271 cases of flat epithelial atypia (FEA) diagnosed by breast core biopsy. Breast Cancer Res Treat. 2012;133:659-66.

37. Bianchi S, Bendinelli B, Castellano I, et al. Morphological parameters of flat epithelial atypia (FEA) in stereotactic vacuumassisted needle core biopsies do not predict the presence of malignancy on subsequent surgical excision. Virchows Arch. 2012;461:405-17.

38. Biggar MA, Kerr KM, Erzetich LM, et al. Columnar cell change with atypia (flat epithelial atypia) on breast core biopsy-outcomes following open excision. Breast J. 2012;18:578-81.

39. Khoumais NA, Scaranelo AM, Moshonov H, et al. Incidence of breast cancer in patients with pure flat epithelial atypia diagnosed at core-needle biopsy of the breast. Ann Surg Oncol. 2013;20:133-8.

40. Saladin C, Haueisen H, Kampmann G, et al. Lesions with unclear malignant potential (B3) after minimally invasive breast biopsy: evaluation of vacuum biopsies performed in Switzerland and recommended further management. Acta Radiol. 2016;57:815-21.

41. Mooney KL, Bassett LW, Apple SK. Upgrade rates of high-risk breast lesions diagnosed on core needle biopsy: a single-institution experience and literature review. Mod Pathol. 2016;29:1471-84.
42. Brandt SM, Young GQ, Hoda SA. The "Rosen Triad": tubular carcinoma, lobular carcinoma in situ and columnar cell lesions. Adv Anat Pathol. 2008;15:140-6.

43. Verschuur-Maes AH, van Deurzen $\mathrm{CH}$, Monninkhof EM, et al. Columnar cell lesions on breast needle biopsies: is surgical excision necessary? A systematic review. Ann Surg. 2012;255: 259-65.

44. Sneige N, Lim SC, Whitman GJ, et al. Atypical ductal hyperplasia diagnosis by directional vacuum-assisted stereotactic biopsy of breast microcalcifications. Considerations for surgical excision. Am J Clin Pathol. 2003;119:248-53.

45. Ely KA, Carter BA, Jensen RA, et al. Core biopsy of the breast with atypical ductal hyperplasia: a probabilistic approach to reporting. Am J Surg Pathol. 2001;25:1017-21.

46. Nguyen CV, Albarracin CT, Whitman GJ, et al. Atypical ductal hyperplasia in directional vacuum-assisted biopsy of breast microcalcifications: considerations for surgical excision. Ann Surg Oncol. 2011;18:752-61.

47. Moinfar F. Flat ductal intraepithelial neoplasia of the breast: a review of diagnostic criteria, differential diagnoses, moleculargenetic findings, and clinical relevance--it is time to appreciate the Azzopardi concept! Arch Pathol Lab Med. 2009;133: 879-92. 